\title{
¿Camilo Fals Borda y Orlando Torres Restrepo? Diálogos y encuentros
}

\author{
¿Camilo Fals Borda and Orlando Torres \\ Restrepo? Dialogues and encounters
}

Nicolás Armando Herrera Farfán*

\begin{abstract}
Resumen
Este artículo recoge los elementos de sintonía ética, epistémica y política entre Orlando Fals Borda y Camilo Torres Restrepo, utilizando para el análisis el concepto guía de campo de Pierre Bourdieu. En el primer campo -el ético- se analiza la influencia del presbiterianismo costeño en Fals y la conversión al catolicismo de Camilo Torres. En el segundo campo -el epistémicoel ensayo plantea la evolución de ambos hacia la necesidad de pensar en una sociología latinoamericana crítica y descolonizada para construir una acción en favor del cambio social y político. El tercer campo de análisis es el político, donde se muestran las coincidencias en la perspectiva que asumen ambos sociólogos para estudiar las relaciones de dominación y explotación, articuladas a las dinámicas de violencia.
\end{abstract}

Palabras clave: campo ético, campo epistémico, campo político, sociología latinoamericana crítica.

\begin{abstract}
The essay gathers the elements of ethical, epistemic and political harmony between Orlando Fals Borda and Camilo Torres Restrepo, using the field guide concept of Pierre Bourdieu for the analysis. In the first field - the ethical one - there is an analysis of the influence of coastal Presbyterianism in Fals and the conversion to Catholicism of Camilo Torres. In the second field -the epistemic one- the essay proposes the evolution of both towards the necessity to think of a critical and decolonized Latin American sociology to build an action in favor of a social and political change. The third field of analysis is the political, which shows the coincidences in the perspective assumed by both sociologists to study the relations of domination and exploitation, articulated to the dynamics of violence.
\end{abstract}

Keywords: critical latin american sociology, ethical field, epistemic field, political field.

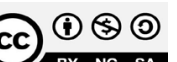

RECIBIDO: 20 DE JULIO DE 2019 | ApROBADO: 2I DE OCTUBRE DE 2019

Cómo CITAR ESTE ARTICULO

Herrera Farfán, N. (2020). ¿Camilo Fals Borda y Orlando Torres Restrepo? Diálogos y encuentros. Collectivus, Revista de Ciencias Sociales, 7(1), 75-88. DOI: https://doi.org/10.15648/Collectivus.vol7num1.2020.2533

* Psicólogo e investigador del Instituto de Estudios de América Latina y el Caribe. Universidad de Buenos Aires (IEALC-UBA). Departamento de Psicología. Dpto. 6. Lanús Oeste, Provincia de Buenos Aires, Argentina.nherreraf@gmail.com 


\section{Introducción}

Existen muchos estudios en torno a la vida y obra de Orlando Fals Borda y Camilo Torres Restrepo. En ellos se explicita su coincidencia histórica. En efecto, Orlando Fals Borda y Camilo Torres Restrepo nacieron en la década de 1920 e hicieron parte de la llamada "Generación de La Violencia": Fals Borda nació en Barranquilla en 1925 en el seno de una familia presbiteriana y acunado por el ethos caribeño, el mismo de García Márquez, y Torres Restrepo en Bogotá en 1929 en una familia de librepensadores de tradición católica.

Por otra parte, ambos se educaron afuera del país. Orlando estudió en Estados Unidos (en lowa, Minneapolis y Florida) y Camilo entre Bélgica (Lovaina) y Estados Unidos (Minneapolis).

Finalmente, ambos regresaron a Colombia casi de manera simultánea: a finales de la década de 1950. Fals Borda venía de Brasil, luego de participar en la misión consultora de la Organización de Estados Americanos (OEA) y como miembro del equipo de la Organización de las Naciones Unidas para la Alimentación y la Agricultura (FAO, por sus siglas en inglés) para la implementación de la política sobre mecanización intermedia en aquel país, luego de sus estudios en sociología rural. Mientras que Torres Restrepo venía luego de sus estudios de sociología (con énfasis en la sociología urbana y del trabajo), de conocer experiencias progresistas de la Iglesia y procesos comunistas europeos y de promover la articulación de jóvenes intelectuales colombianos y colombianas residentes en el extranjero -con el Equipo Colombiano de Investigación Socio-Económica (ECISE), luego rebautizado como Equipo Colombiano ProEstudio y Progreso (ECEP)-.

El regreso al país coincidió con la implementación del Frente Nacional, aquel pacto político hecho por las élites de los partidos Liberal y Conservador que, bajo el discurso de la superación de La Violencia, establecía un modelo democrático-institucional restrictivo, que cerraba las puertas a la participación de las tercerías políticas (especialmente al comunismo) y se asentaba la represión que significaba el Estado de Sitio. La implementación fue más o menos simple: durante dieciséis años (1958-1974) se intercalaron la presidencia de la república y se repartieron a partes iguales las cuotas burocráticas y presupuestales del Estado.

Estas condiciones históricas y personales fueron determinantes para el rol protagónico que ambos jugaron en los orígenes de la institucionalización de la sociología académica colombiana. A sus nombres se sumaron luego el padre Gustavo Pérez Ramírez (PhD. de la Universidad Católica de Lovaina) y María Cristina Salazar (PhD. de la Universidad Católica de América, en Washington).

Ahora bien, esta coincidencia, sobre la cual se ha llovido sobre mojado, resultaría siendo anecdótica si sólo se explica y comprende en función del azar histórico. De allí que resulte prioritario aproximar elementos de sintonía ética y de transformaciones epistémicas y políticas de ambos, que permitan advertir un horizonte común.

En las siguientes líneas nos proponemos plantear y establecer algunos encuentros y diálogos sostenidos por ellos en torno a tres campos (Bourdieu, 2002). El primero de ellos es ético y se constituye en el punto de partida y en el núcleo humanístico. El segundo es epistemológico y alude a la crítica del marco científico dominante y el planteamiento de una nueva perspectiva de saberes-acción (neo-paradigma). El tercero, es político, y se manifiesta en la proposición de un nuevo horizonte renovado, enraizado en la cultura con las armas teóricas de la crítica. De allí que nuestra tesis central sea la comprensión de la relación entretejida entre teología, ciencia y política, lo que equivale a la indivisibilidad comprensiva entre Amor Eficaz, Investigación-Acción Participativa y Socialismo Raizal.

Collectivus, Revista de Ciencias Sociales | Vol. 7 No. 1: pp. 75-88. Enero - Junio, 2020 | ISSN 2382-4018 
Para ello, abordaremos la cuestión desde un marco interpretativo distinto al impuesto por la modernidad, alejándonos del prejuicio jacobino secularista. De tal manera, intentamos aportar elementos al debate de la relación fe-ciencia-política en Orlando Fals Borda (que es menos evidente que la de Camilo Torres) pues, como afirma (Pérez, 2010): "poco o nada se ha explorado el transfondo religioso de Orlando Fals, transfondo que tiene su origen en su familia y en la Iglesia Presbiteriana de Colombia" (p.26).

Al mismo tiempo, propendemos a superar la manida, pero perviviente, asepsia científica o neutralidad valorativa. Entonces, tomaremos en consideración los aportes de la corriente praxiológica latinoamericana de la liberación (de la cual, en parte, Orlando y Camilo son pioneros). Por otra parte, adoptamos la categoría de totalidad expuesta por Georg Lukács en su célebre libro Historia y conciencia de clase, donde afirma que "La referencia a la totalidad concreta y a las resultantes determinaciones dialécticas apunta más allá de la mera descripción y arroja la categoría de la posibilidad objetiva" (Lukács, 1984, pp.130-131).

\section{Campo ético y espiritualidad}

Orlando Fals Borda fue educado en el seno de una familia presbiteriana barranquillera y desarrolló sus primeras experiencias comunitarias y colectivas alrededor de la Iglesia y del Colegio Americano de aquella ciudad. Allí desarrolló un influjo positivo hacia la gente humilde, un sentido del ecumenismo, entendido como actitud, y una ética social que determina la manera de ver los procesos sociales, para concebirlos en una perspectiva trascendente o de preocupación última "y las implicaciones que derivan para la conducta personal y social, incluyendo visiones de cambios necesarios en las relaciones sociales" y que se expresan en tres éticas: del altruismo, del compromiso y del cristianismo ecuménico (Castillo, 2010, pp.20-21).

En ese entonces, el presbiterianismo costeño estaba encabezado por Richard Shaull, un reverendo norteamericano formado en el Princeton Seminary que gozaba de una formación profesional significativa y de una concepción del protestantismo extralitúrgico que se guiaba por la consigna calvinista "ecclesia reformata sempre reformanda". De acuerdo con esta concepción, Shaull promovía la organización y comunicación juveniles, así como los talentos particulares, vinculando a la Iglesia con la sociedad, principalmente con los pobres, en un ambiente abierto, tolerante y ecuménico, proyectando una dimensión social de la fe. No en balde, Shaull es considerado uno de los fundadores de la Teología de la liberación.

Por su parte, Camilo Torres Restrepo había sido educado en el seno de una familia de librepensadores que practicaba los ritos católicos. Su conversión al catolicismo se dio a finales de sus estudios secundarios cuando entabló relaciones con una misión de frailes dominicos franceses que encarnaban la nouvelle théologie y proponía una iglesia comprometida con el amor al prójimo y las necesidades de sus hermanos y hermanas. Hablar de "conversión" en Camilo implica una opción consciente. Como él mismo señala en su declaración del 24 de junio de 1965:

Yo opté por el cristianismo por considerar que en él se encontraba la forma más pura de servir a mi prójimo. Fui elegido por Cristo para ser sacerdote eternamente, motivado por el deseo de entregarme de tiempo completo al amor a mis semejantes (Torres, 1970, p.376).

A partir de allí decidió hacerse seminarista y luego sacerdote. Este horizonte humanista que Camilo descubrió en el catolicismo fue complementado con la dimensión sociológica, principalmente influenciado por François Houtart, un canónigo y sociólogo belga, que lo impulsó a estudiar sociología en Lovaina como complemento de su formación sacerdotal. 
Así pues, Orlando y Camilo tienen como matriz ética-espiritual común al cristianismo, aunque se expresen dentro de las corrientes presbiteriana y católica. Esto significa dos cosas: por un lado, que ambos parten de un "pensar cristiano" y por el otro, que beben de las mismas fuentes éticas.

De acuerdo con Dussel (1973) el "pensar cristiano" alude a una acción rumiante que tiene cinco características: (a) tiene como condición la crisis, lo que significa un distanciamiento de la comprensión cotidiana para juzgar la realidad desde afuera; (b) es un pensamiento "riesgoso" y anti-sistémico, llamado a desmitificar todo lo que siendo relativo se ha absolutizado, posicionándose más-allá de las ortodoxias; (c) es "creativo" e histórico, en la medida que se plantea los problemas por sí mismo, sin imitaciones, y aprende a elaborar preguntas antes que buscar soluciones desde la propia historicidad (realidad y contexto); (d) es concreto, pues se constituye en una praxis que tiende puentes entre los fundamentos teóricos y la práctica comprometida con la realidad concreta; $y$, (e) es profético, en la medida que busca caminar con el pueblo errante (que yerra) para brindar herramientas de comprensión del sentido del presente.

Por otra parte, la eticidad cristiana tiene como núcleo fundamental el reconocimiento de la Otredad. La Alteridad de las víctimas del sistema de dominación (pobre, viuda, huérfano, extranjero) tiene su origen en la tradición semita y cristiana.

La ética judeo-cristiana parte de la proximidad originaria del sujeto ante el sujeto. Este encuentro caraa-cara permite la revelación del Otro (epifanía) en tanto persona.

En el horizonte del desierto (arábigo) un beduino semita, palestino aún como los judíos (...) avanza como un punto lejano; al aproximarse se va descubriendo de qué clan, de qué tribu, de qué pueblo es miembro. Más cercano ya, en la proximidad, el semita (...) establece el cara-a-cara. Paním el paním dice el dialecto palestino llamado hebreo. Prósopon prós prósopon, en la traducción griega. Es la categoría que funda todas las categorías críticas. (Dussel, 2016, p.13).

Se trata de "una categoría estrictamente racional de extrema originalidad en la historia de la filosofía política, la meta-categoría de la exterioridad política, de la Alteridad ética, que, siendo de origen judío, adquiere en las enseñanzas de Jeshúa [Jesús] una centralidad originante central, y que se instala como núcleo de todo un conjunto de culturas" (ob. Cit).

Este trasfondo ético proveniente del humanismo semita (Dussel, 1969) se cristalizará en la figura de Jesús de Nazaret y se desarrollará en las proposiciones de Pablo de Tarso, quien advierte la necesidad del reconocimiento del sujeto y su primacía sobre la ley. Se trata de una ética de la vida y para la vida, material y no ontológica. Por ello, para Hinkelammert (2010) se halla en el centro del desarrollo de todo pensamiento crítico.

Así pues, la ética judeo-cristiana se constituye en el punto de partida de Orlando Fals Borda y Camilo Torres Restrepo. Esta los condujo al compromiso con las víctimas del sistema y les exigió superar la ética del capitalismo y desarrollar sus vidas en torno a la prioridad de la otredad (mayoritariamente marginalizada) y recuperar la corporalidad del sujeto.

De hecho, algunos analistas han planteado que en los orígenes institucionales de la sociología colombiana se entremezclan la "ética" y la "mística" cristiana con un horizonte de "redención" de las víctimas del sistema y una pasión "por el servicio social, la responsabilidad colectiva y el deber individual" (Pereira, 2009; Sánchez, Pérez, Rebolledo y Rodríguez, 2019), mientras que José Jaramillo señala la existencia de un "currículo oculto" debido al peso de Camilo y Orlando (Moreno, 2017, p.21). 
Así pues, un primer elemento que podemos poner sobre la mesa de discusión es que la proposición del "amor eficaz" propuesto por Camilo Torres Restrepo, en realidad es el resultado de la actualización colombiana de este piso ético común, por lo cual resulta imprescindible señalar que, en virtud de los diálogos y encuentros éticos entre ambos, también hace parte constitutiva de la apuesta posterior de Orlando Fals Borda.

\section{Campo epistemológico}

En Estados Unidos, Orlando Fals Borda cursó su maestría en la Universidad de Minnesota bajo la supervisión de Lowry Nelson y su doctorado en la Universidad de Florida bajo la observancia de T. Lynn Smith.

Era un tiempo en el que la sociología rural estaba en expansión y se vislumbraba como una promesa que solucionaría los problemas de la pobreza rural y el aumento creciente de la demanda de alimentos debido a la migración del campo a la ciudad, además de un conjunto de estrategias que contrarrestarían los procesos de violencia. Dicha sociología asumía una perspectiva cercana al planteamiento de Robert K. Merton de la Universidad de Columbia y de la Escuela de Chicago, que al de Talcott Parsons: era afín a la interdisciplina, la microsociología y el análisis histórico (Moreno, 2017, p.23).

En ese momento, el modelo sociológico dominante era estructural-funcionalista y compartía rasgos con las ciencias naturales: validez universal, pretensión de objetividad, neutralidad valorativa, asepsia política, prioridad de uso de estrategias empíricas y métodos cuantitativos, sobre la base de paradigmas cerrados, deductivos y lineales tales como el positivismo y el mecanicismo. Este modelo pretendía construir un conocimiento "exacto" y "objetivo" (como mero reflejo de la realidad) que formulara "leyes universales". Para ello, se requería limitarse a "lo medible" y "cuantificable" considerando la subjetividad como metafísica. Entonces, abogaba por un modelo homeostático que tendía a la integración y el equilibrio social.

Dicho modelo acogía las ideologías liberales de "desarrollo", "modernización" y "reformismo", así como la teoría individualista del Orden, reduciendo el "hecho social" a una "condición de individualidad". Por estas razones, y otras más, era denunciado como un mecanismo ideológico legitimador del orden social burgués, liberal y capitalista, una sociología burguesa. Esta proposición sociológica se oponía a las nociones de "conflicto" y "lucha de clases" propias del marxismo, en un momento en el que el marxismo dominante se desarrollaba desde una formalización dogmática heredera del estalinismo: el marxismo-leninismo caracterizado por el estatismo y anti-intelectualismo, que seguía la línea evolucionista y homeostática como rasgos característicos de la Modernidad (Pereira, 2009)

Por su parte, Camilo Torres Restrepo estudió sociología en la Universidad Católica de Lovaina. Allí, la sociología dependía mucho de la economía, el derecho y la filosofía, bajo un modelo especulativo con instrumentos analíticos.

La principal influencia analítica de la sociología lovaniense era la Doctrina Social de la Iglesia, que partía del tomismo y el neotomismo, y establecía una centralidad ética de la justicia y el bien común. Se trataba de un modelo inter-clasista, es decir, que partía de la comprensión de la sociedad como capas sociales superpuestas, que debían armonizarse para alcanzar el bien común. De aquí se deriva que no había una crítica de la lógica del capitalismo, sino de sus excesos.

Sin embargo, cuando Camilo llegó a Lovaina, la sociología estaba introduciendo el empirismo norteamericano, donde primaba la realidad, debida a la influencia de la Universidad de Chicago. 
Esta formación fue complementada con cursos especializados en campos relacionados con la sociología urbana y la sociología del trabajo por un período no mayor a tres meses en la Universidad de Minnesota. En conclusión, la sociología aprendida por Camilo buscaba amalgamar la perspectiva analítica europea con las herramientas empíricas de análisis social norteamericanas (Herrera y López, 2018; Herrera y López, 2014). Por lo anteriormente expuesto podemos afirmar que la formación sociológica de Orlando Fals Borda y Camilo Torres Restrepo no difirió en lo fundamental, aunque el énfasis de cada uno esté delimitado: Orlando más enfocado a la sociología rural y Camilo a la sociología urbana.

Sobre esta base científica iniciaron el proceso de institucionalización disciplinar colombiano a su regreso al país, que coincidía con los procesos de institucionalización que se advertían en otros países del continente, principalmente Brasil, Argentina, Chile y México con figuras como Florestan Fernandes, Gino Germani y Pablo González Casanova. El telón de fondo histórico estaba signado por la Revolución cubana y la implementación de la Alianza para el Progreso y el Frente Nacional que impulsaba un proyecto de modernización del Estado y de "desarrollo" del país.

El proceso de institucionalización colombiano tuvo algunos núcleos problemáticos fundamentales: la reforma agraria, la acción comunal y la modernización del Estado como vías para la participación y democratización del país. Dichos núcleos fueron desarrollados en focos específicos que estuvieron encabezados o influenciados por ambos: el Departamento de Sociología de la Universidad Nacional de Colombia -luego convertido en Facultad-; la carrera de Sociología de la Pontificia Universidad Javeriana (de la mano de María Cristina Salazar); el Instituto Colombiano de Desarrollo Social, ICODES (dirigido por Gustavo Pérez Ramírez); el Instituto de Administración Social de la Escuela Superior de Administración Pública, IAS-ESAP; el Comité Técnico del Instituto Colombiano para la Reforma Agraria, INCORA y el equipo promotor de la ley de Acción Comunal que propuso la "Plataforma de acción comunal" y que sería la base de la ley que la reglamentaría en el país (conformado además por Orlando Quijano).

Ahora bien, estamos ante un período de investigación empírica y compromiso con las reformas sociales, de síntesis científica y compromiso con la acción, que se puede definir como reformista. Se caracteriza por la comprensión del compromiso social del cristiano y el científico bajo los principios de la Doctrina Social de la Iglesia, el modelo estructural-funcionalista y la ideología desarrollista. Entonces, concebían el trabajo científico y político "desde arriba", por medio de dispositivos institucionales y la conformación de núcleos de trabajo científico "objetivo" y comprometido más allá de las divisiones ideológicas o partidistas. En este período consideraban -de manera idealista y un tanto ingenua- que era posible que las comunidades urbanas y campesinas alcanzarían procesos de auto-desarrollo a través de los diversos programas, leyes y proyectos estatales.

Es un momento en el que entran en contacto más directo (aunque Fals Borda tenía su experiencia previa con los campesinos cundiboyacenses de la década anterior) y les permite tomar el pulso a la cuestión social comprendiendo científicamente los problemas sociales candentes (como La Violencia) y captan de cerca lo que dicen las estadísticas: el sentido de las urgencias. Es un momento de encuentro cara-a-cara con el pueblo (momento ético de la epifanía del sufrimiento del Otro).

Entonces, descubren que los modelos teóricos euroamericanos aprendidos resultaban insuficientes para comprender la realidad de una sociedad en crisis, cuyos procesos de violencia no sólo debían ser vistos como "patología" y "desviación" sino como posibilidades de "cambio socio-cultural" de las comunidades. La creencia en el cambio social "desde arriba" se fue diluyendo progresivamente ya que los sectores sociales dominantes organizaban la estructura del Estado para mantener y defender sus privilegios, y no estaban dispuestos a ceder. 
Lenta, pero decididamente, fueron avanzando hacia un momento más analítico-reflexivo. Se requería un nuevo marco epistemológico que fuera más allá de las capas sociales y del orden social para desarrollar un pensamiento social más realista viendo la realidad con los ojos de las clases oprimidas y en función de sus intereses. Esta reformulación teórica e interpretativa de las "categorías ideales" de los libros y la academia (v.g. democracia, poder, violencia y orden social) no es producto de la escolástica academicista sino del contacto con la realidad. Así se fueron acercando a las teorías del conflicto social y al marxismo.

A partir de 1961, Camilo Torres Restrepo comenzó el proceso de radicalización paradigmática en términos teóricos y prácticos, expresando una angustia generacional. En la teoría, en su trabajo "El problema de la estructuración de una auténtica sociología latinoamericana" señaló la necesidad de la descolonización y de las búsquedas del pensamiento propio, desde modelos interdisciplinarios articulados con las comunidades con las cuales se proponía trabajar (Torres, 1970, pp.159-165). En la práctica, desarrolló el camino con la creación del Movimiento Universitario de Promoción de la Comunidad (MUNIPROC) y del Consejo Interfacultades de Desarrollo de la Comunidad en la Universidad Nacional de Colombia, cuestionando el modelo de "feudalización europeizante" de las facultades que limitaba la comprensión compleja de los problemas sociales.

A estos elementos le subyace una categoría ética central, proveniente de la matriz cristiana: el compromiso. Esta categoría es definida en el mismo sentido dado por Jean Paul Sartre:

Los franceses tienen la ventaja de emplear dos palabras que dramatizan las diferencias que en el español quedan cobijadas por una sola: engagement y compromis. La idea sartriana de engagement, como se sabe, es la que más se acerca al concepto de "compromiso" que queremos definir para la sociología de la crisis: es la acción o la actitud del intelectual que, al tomar conciencia de su pertenencia a la sociedad y al mundo de su tiempo, renuncia a una posición de simple espectador y coloca su pensamiento o su arte al servicio de una causa (Fouskas, Gikopoulou, Ioannidi, y Koulierakis, 2019). El otro compromiso, el compromis francés, implica el transigir, hacer concesiones, arreglos, arbitrajes, entregas o claudicaciones (Fals Borda, 1971, p.188).

Por otra parte, el "compromiso" al que alude Fals Borda se relaciona con el "inconformismo científico" de Torres Restrepo. Es decir, no se trata simplemente de estudiar y analizar la realidad, sino que es necesario un vínculo definitivo con la clase popular. Por eso añade:

Creo que es elemental para una persona que sea honrada, que tenga una visión científica de la realidad, una actitud objetiva ante la realidad del país, si está en contacto con esa realidad en una forma inmediata, necesariamente tiene que comprometerse (Torres, 1965a, p.149).

Este "compromiso revolucionario" exige una confrontación subjetiva, una ruptura afectiva-efectiva que conduzca al desapego de los símbolos de prestigio burgués, llamados por Camilo como "formas exteriores de vida de las clases dirigentes" y por Fals Borda como "títulos de dominio" y "prebendas de los poderosos":

Los estudiantes [v.g. los intelectuales] participan subconscientemente de los valores de esta sociedad, aunque conscientemente los repudien. (...) Mientras no seamos capaces de abandonar nuestro sistema de vida burgués no podremos ser revolucionarios.

El inconformismo cuesta y cuesta caro. Cuesta descenso en el nivel de vida, cuesta destituciones de los empleos, cambiar y descender de ocupación, cambiar de barrio y de vestido. (...) Es necesario que comencemos ya. Que nos mezclemos con las masas, que vivamos, no solamente para los pobres, sino con los pobres y como pobres (Torres, 1965b, pp.155-156). 
El sociólogo y socióloga comprometidos, entonces, se convierten en subversores morales y se transforman en representantes políticos y teóricos de otra clase, tal como lo desarrolló (Lowy, 2010) en su estudio sobre el joven Marx.

La impugnación de los 'marcos' dominantes exige una ruptura con ellos y el adentrarse en un proceso creativo (poiético) a fin de abrir caminos distintos de aproximación a la realidad, con y desde las víctimas sufrientes del sistema de dominación capitalista.

Entonces, se fue desarrollando una nueva disposición de compromiso-acción que equivalía a estudiar la realidad para transformarla, dado que la ciencia social dejaba de ser una auto-referencia para convertirse en una herramienta del cambio social. La IAP se fue cristalizando en este proceso.

De esta manera, Orlando y Camilo descubrieron la necesidad de pensar sociológicamente, en una etapa teórica donde se estaba inventando el camino de una sociología latinoamericana, desarrollando algunos elementos comunes tales como:

$\gg$ la concepción de una sociología empírica y aplicada, tendiente al trabajo de campo en el terreno;

$\gg$ la definición de la sociología como un instrumento necesario para construir una acción en favor del cambio social y político, yendo más allá del momento descriptivo y analítico;

$\gg$ la comprensión de un modelo interdisciplinario para afrontar los problemas en perspectiva de totalidad, superando los(Moreno, 2017) "feudos profesionales";

$\gg$ la valoración del saber popular, que les impidió reconocer a la academia como la depositaria privilegiada y exclusiva del desarrollo de la ciencia (Rojas G, 2010);

$\gg$ el origen religioso de su compromiso científico y social en favor de la transformación de la realidad de las víctimas del sistema de dominación;

$\gg$ el horizonte de construcción de un pensamiento propio, descolonizado, reenfocando lo que habían aprendido, para que la escuela científica fuera colombiana y no mimesis de la europea o norteamericana.

Orlando y Camilo encarnaron e impulsaron este nuevo modelo sociológico de compromiso. Orlando desde una posición de "resistencia cívica" y Camilo desde una postura "beligerante". Así lo confirmó Fals Borda (2007) en uno de sus últimos discursos:

En el nacimiento de la IAP hubo dos tendencias entre intelectuales: la beligerante representada por Camilo Torres -que vio en las armas y en las guerrillas históricas la única salida posible; y otra vía de resistencia cívica que asumieron instituciones autónomas como la Fundación La Rosca que yo presidí, el CINEP de los padres jesuitas de avanzada, y movimientos críticos tipo Freire, como en Fecode (Federación Colombiana de Educadores) (p.396).

Las categorías "subversión", "compromiso" y "anti-conformismo científico" los fueron conduciendo a una ruptura con el estructural-funcionalismo. No había ciencia aséptica, apolítica e incontaminada, sino una gran hipocresía que favorecía la dominación.

En el fondo se fue desplegando progresivamente un marco conceptual distinto que fructificaría en la Investigación-Acción Participativa. Ciertamente, los diálogos y encuentros epistémicos redundaron en este esfuerzo neo-paradigmático. 


\section{Campo político}

Desde sus estudios con la población campesina cundiboyacense de la década de 1950, Orlando Fals Borda fue construyendo una idea distinta a la que tradicionalmente se tenía de la población campesina, que era vista como pasiva e ignorante, separada del "grupo educado" de la sociedad, con una "supuesta herencia atávica de pasividad campesina". En efecto, existía una "concepción vertical, colonial y degradante del campesinado colombiano que mantenía la élite" (Moreno, 2017, pp.96-97). En su lugar, comienza a concebirla como inteligente, creativa, con capacidad de análisis y de generación de cambios en su cotidianidad, algo inédito hasta entonces y que se constituye en uno de sus primeros aportes esenciales.

En su trabajo "Acción comunal en una vereda colombiana" escrito con Nina Chaves sentencia:

Para la élite, el pueblo no ha sido sino un grupo heterogéneo de personas ignorantes y miserables, merecedoras de su suerte como siervos de la gleba, a quienes hay que señalar la vía y conducirlos como acémilas en recua. Muchas personas en potestad conservan para la clase campesina la misma y colonial actitud, en el sentido de que ella se compone de indios, infantes en fe y en la civilización (Moreno, 2017, p.97).

Y en su monografía de los años cincuenta "Teoría y realidad del cambio sociocultural" identifica que las resistencias y negaciones campesinas a las propuestas modernizantes tenían razones técnicas y de tipo económico además de criterios tales como "mecanismos de autodefensa basados en la tradición como valor social, la presión social coercitiva y las creencias religiosas" (ob. Cit, p.63). Así, señalaba que era necesario "echar por tierra la idea de que estos campesinos son gentes irremediablemente conservadoras, incapaces de adoptar lo nuevo y aún de tener iniciativas valiosas" (ob., Cit, 2017, p.165).

En las décadas siguientes ampliará su valoración del campesinado al "pueblo", en el que había que confiar y que podía participar en el proceso de investigación para transformar su realidad; es decir, primero como reconocimiento de su inteligencia y después como sujeto epistemológico.

Por su parte, Camilo Torres Restrepo comprende que en Colombia sobrevivían dos grupos sociales que enfrentaban sus intereses epistemológicos, culturales y económicos: una mayoría dominada y una minoría dominadora. La "élite" y el "campesino"/"pueblo" de Orlando será definido por Camilo como "clase oligárquica" y "clase popular". En un reportaje concedido a unos alemanes en 1965, Camilo habló de la "clase popular":

Con la palabra clase popular yo quiero dar a entender los pobres de Colombia. Naturalmente que desde un punto de vista estrictamente sociológico yo comprendo que es una expresión bastante vaga, pero es la expresión que el pueblo entiende. (...) pero para designar a los pobres, y para no referirme únicamente a los obreros, sino también a los campesinos, he utilizado esa expresión de clase popular (Torres, 1970, p.426).

Ahora bien, Camilo comprende que cada una de estas "clases" desarrollaba su propia sub-cultura sin comunicación entre ambas, por ejemplo, señaló que la sub-cultura de la clase oligárquica era urbana, elitista y extranjerizante, dependiente de los intereses norteamericanos, cumpliendo funciones intermediarias al capital monopolista transnacional. Por esta vía, Camilo concluyó que los pobres del sur y los ricos del norte no eran fruto de un hecho geográfico o natural, sino una construcción social.

La clase oligárquica controlaba monopólicamente los medios de producción (economía), la burocracia de todas las instituciones estales (política), los medios de comunicación, los relatos pedagógicos y la jerarquía eclesiástica (cultura, ideología y espiritualidad) y las fuerzas armadas (violencia institucional). 
De esta manera, la clase oligárquica (minoritaria) se constituía en un "grupo de presión" eficaz, que dominaba todo bajo el principio de conformismo, y los partidos políticos tradicionales se organizaban policlasistamente, constituyéndose en el mecanismo de integración de la sociedad e impidiendo la formación de partidos de clase.

Entonces, se comprometió abiertamente en el campo político a mediados de 1965 para promover el cambio social desde las bases y desde el reagrupamiento de las izquierdas, es decir, convertir a las mayorías en un "grupo de presión" popular. Esta tarea era concebida como "cristiana y sacerdotal", incorporando la referencia cristiana, la espiritualidad y la renovación personal a la lucha política.

Así, Camilo propuso el Frente Unido del Pueblo desde una posición anti-dogmática basada en la realidad y no en consignas ideológicas, y en un proceso dialógico que dirimiera las diferencias y metabolizara las coincidencias en un proyecto político unitario cuyo horizonte sería el socialismo. Posteriormente, su compromiso ético con los prójimos y prójimas lo condujeron a la lucha armada, decisión consciente y coherente.

La prematura muerte de Camilo Torres Restrepo en 1966 impactó de manera rotunda el camino de Orlando Fals Borda quien, en 1967, publicó un libro que marcaría el rumbo irreversible hacia un nuevo paradigma: La subversión en Colombia. Este libro fue dedicado a la memoria de Camilo con una alusión particular: "A la memoria de Camilo Torres Restrepo, fundador del Socialismo Raizal e impulsor de los primeros esfuerzos para alcanzarlo en Colombia".

De hecho, en ese libro, dedica un apartado especial para analizar la propuesta del Frente Unido del Pueblo. Dicho movimiento se erigía en el aparato de la "subversión moral" que enfrentaba al orden social burgués instituido con el Frente Nacional. Se trataba de una subversión que amalgamaba ingredientes religiosos con la reiteración de la utopía socialista con un acento determinante en el pluralismo. Esta utopía neo-socialista partía del ecumenismo religioso basado en el concepto de koinonia ("comunidad") cuyos tres principios rectores son: amor, libertad (justicia) y sabiduría (Fals Borda, 2008/1967, p.210).

Orlando Fals Borda, que participó de la experiencia del Frente Unido del Pueblo reflexionó teóricamente sobre el socialismo raizal a partir de la década de 1980.

Entonces, pudo establecer que no se trataba de una "utopía clerical" sino de un ecumenismo político que sintetizaba las corrientes cristiana y marxista con la historia y tradición de lucha del pueblo colombiano, 'revolcando' los morrales culturales e históricos para encontrar elementos alternativos de origen propio. El neo-socialismo pretendía construir una sociedad abierta y justa, enfatizando el desarrollo del poder popular-comunal, fortaleciendo y promoviendo las comunidades de base, el cooperativismo y la intervención de los obreros en las empresas.

El punto de partida de tal socialismo son los cuatro pueblos originarios que representan las raíces telúricas precapitalistas y alimentan la idiosincrasia regional y la 'colombianidad': indígenas primarios, negros libres de origen africano, campesinos-artesanos pobres antiseñoriales de origen hispánico y colonos autonómicos o nativos-mestizos. El ethos de estos pueblos es de naturaleza colectiva y se mantiene vivo por medio de tácticas de supervivencia como "la acomodación, la simbiosis y el sincretismo; y también la revuelta, la contraviolencia y la adopción selectiva" (Herrera Farfán y López Guzmán, 2012, pp.399-411).

Algunos de sus valores son: solidaridad, libertad, dignidad, autonomía, equidad, justicia, respeto por la vida y el entorno, altruismo y cooperación (Herrera Farfán y López Guzmán, 2012, pp.399-408). 
El socialismo raizal exige dos movimientos simultáneos: hacia 'lo profundo' y hacia 'lo externo'. Hacia 'lo profundo' quiere decir el rastreo de las raíces de nuestros pueblos para hallar el ethos ecológico y no-capitalista, con sus valores y cosmovisiones, recuperando las savias ancestrales "con sus propios Aristóteles y Pitágoras, aunque no sepamos aún sus nombres vernáculos: a todos hay que buscarlos en la floresta aún virgen de nuestra historia auténtica, la que comienza antes de 1492" (Herrera Farfán y López Guzmán, 2012, p.89). Hacia 'lo externo' nos exige enfrentarnos al mito hegeliano de la 'historia universal' con su secuencia histórica Egipto-Asiria-Grecia-Roma-Europa con epicentro en el Mar Mediterráneo, dado que nuestras diferencias con Europa son notables:

Nuestra tradición es más compleja y amplia que la de los europeos, como lo es también la fauna, flora y alimentos en comparación con los de las zonas templadas de la tierra. Aquí el sol es más radiante y en los Andes tenemos las cuatro estaciones en un solo día. Por eso, a aquella secuencia formativa del Mediterráneo que nos han inculcado desde la cuna, debemos añadir nuestro propio panteón anfibio con las maravillas explicativas de los grupos humanos que ocuparon e hicieron producir antes que nadie todas estas tierras, empleando para ello una cadena formativa muy diferente: la Maya-Arawak-Chibcha-IncaGuaraní, la de la "América Profunda", que es tanto o más rica que la otra secuencia" (Herrera Farfán y López Guzmán, 2012, pp.89-90).

A su vez, el socialismo raizal plantea tres críticas implícitas a la cultura política y la civilización dominante: al colonialismo intelectual, pues no se trata de un 'calco y copia' de planteamientos ideológicos concebidos por la filosofía europea, preceptos de otros países o traducciones de constituciones; al contenido de la utopía, promoviendo una concepción democrática, flexible, plural y abierta, alejado del modelo restrictivo estalinista y de la "ideología del consenso democrático" propio de la utopía clásica de derechas; a la relación nacional-internacional, asumiendo un horizonte de lucha comunal que reitera la autenticidad regional y nacional sin caer en el chauvinismo o en el mito del "socialismo en un solo país" o en el lastre del fascismo nacionalista; se asume como una lucha dentro del conjunto de las luchas de los pueblos del mundo, con un contenido anti-imperialista y anti-intervencionista.

De esta manera, esta "utopía superior" debe convertirse en el "pegante ideológico" o "cemento estructural" para proyectos ya que se opone al capitalismo ética, ecológica, económica, política, científica social, cultural, espiritual y afectivamente. Este fue el esfuerzo político de la vida de Orlando Fals Borda quien, para Miguel Eduardo Cárdenas, se convirtió en el "portaestandarte de la propuesta revolucionaria elaborada por Camilo Torres Restrepo, idea de la que no desistió hasta su último respiro" (Cárdenas, 2014, p.357).

\section{Reflexiones finales}

En el presente trabajo hemos expuesto los diálogos y encuentros entre Camilo Torres Restrepo y Orlando Fals Borda en los campos ético, epistémico y político y nos hemos interesado principalmente en comprender su relación entretejida.

Una primera reflexión que nos surge es que, para comprender las experiencias de Camilo Torres Restrepo y Orlando Fals Borda es necesario adoptar marcos interpretativos distintos, que nos permitan tender puentes entre espiritualidad, ciencia y política, lo cual nos conduce necesariamente a quebrar el prejuicio jacobino moderno secularista. Resulta imposible intentar avanzar sobre la Investigación-Acción Participativa sin considerar su base en el Amor Eficaz, y sobre el socialismo raizal sin su basamento epistémico. 
En esta clave, podemos repensar que la experiencia de ambos es un aporte simultáneo a la construcción de una contra-religión (o Teología) secular en la que el ser humano sea el ser supremo para el ser humano, y que arrase con las relaciones en las cuales el ser humano sea humillado, violentado, sojuzgado y despreciable, tal como proponía Karl Marx en los Manuscritos económico-filosóficos. Se trata de confluir en un proyecto liberador de la espiritualidad, la ciencia, la política y el territorio que haga frente a la religión secular de la modernidad capitalista cuyo dios-mercado exige el sacrificio de vidas para su supervivencia. El indisociable trípode de Teología-Ciencia-Política que sostiene sus experiencias es patrimonio de una cierta comunidad de saberes-acción críticos desarrollados en Latinoamérica a lo largo del siglo XX en diversas disciplinas y experiencias (v.g. pedagogía, sociología, economía, teología, filosofía, ética, teatro, psicología y política).

Una segunda reflexión alude a la necesidad de estudiar las experiencias como inter-implicadas. Esto equivale a decir que, en nuestro criterio, no hay Orlando Fals Borda sin Camilo Torres, y no habría desarrollo de las tesis esbozadas por Camilo Torres sin el desarrollo posterior de Orlando Fals Borda. En este sentido, podemos señalar que Camilo Torres Restrepo es el primer falsbordiano y Orlando Fals Borda es el más insigne camiliano.

Sin embargo, justicia obliga señalar que los caminos no fueron los mismos, no sólo por los hechos concretos de sus vidas sino las trayectorias asumidas, por lo cual también hay distancias. La radicalidad teórica y vanguardista desarrollada por Fals en muchas ocasiones riñó con sus posturas políticas tibias, reformistas y aún socialdemócratas, que apostaban más por un enfoque institucional y legislativo, de "políticas públicas" y parlamentarismo. La oscilación permanente entre el "socialismo raizal" y el "pacto social liberal", puede evidenciarse en la errática lectura del momento político del uribismo en el "Epílogo" de la edición de 2008 de La subversión en Colombia y en la consideración del Polo Democrático Alternativo (PDA), cuyo programa apuntaba a una reconstitución radical del Estado Social de Derecho, como una suerte de "resurrección" del Frente Unido del Pueblo de Camilo Torres.

Una tercera reflexión es que la herejía teológica, la rebelión intelectual y la disidencia política que ambos representan tuvieron impactos complementarios en los tres campos aludidos, por lo tanto no pueden limitarse a la coyuntura de su tiempo, sino que su lógica y orientación pueden desplegarse de acuerdo con las nuevas perspectivas del tiempo, con la crítica del paradigma capitalista y la proposición de otro paradigma. La influencia de ambos en una nueva espiritualidad, en la sociología académica y comprometida, la descolonización epistemológica, y el compromiso revolucionario, se constituye en una suerte de fantasma que recorre el mundo y habita nuestro tiempo.

Una cuarta reflexión está en el sentido que podríamos advertir una comprensión más profunda de sus experiencias que amplíe la dialéctica establecida por Michael (Lowy, 2010) entre teoría crítica, reflexión y acción social. Es decir, se trata de ir más allá de la praxis marxiana (que entrelaza la teoría y la práctica) y el sentipensamiento falsbordiano (que vincula espiritualidad/afectividad con el pensamiento). La articulación teológica, sociológica y política conduce a una articulación entre la praxis y el sentipensamiento, esto es, entre las dimensiones afectica/espiritual, cognitiva y operativa que podemos definir como senti-praxis.

Finalmente, queremos señalar que las experiencias de Camilo Torres Restrepo y Orlando Fals Borda siguen siendo acicate para no caer en el activismo ciego y epidérmico, y para evitar el intelectualismo abstracto. Su influencia reside más en las preguntas que planteaban que en las soluciones y respuestas que aportaban. Hay que advertir las lecciones y no las repeticiones; comprender las perspectivas y no reducirse a las apariencias. 
Se nos revela como tarea de nuestro tiempo redefinir los objetivos: unidad para enfrentar y superar la lógica sacrificial impuesta por el capital; compromiso ético y primacía de las víctimas del sistema; lucha contra el dogmatismo y la ortodoxia; actualización de métodos, lenguajes y sistemas de legitimación; desarrollos teóricos y analíticos para buscar alternativas; promoción de espiritualidades rebeldes, comprometidas y de liberación.

En tiempos de ofensiva de la dictadura del mercado mundial, que incluye en Latinoamérica nuevos modelos de golpes de Estado, agresiones a procesos democráticos y desarme y reestructuración de las últimas guerrillas marxistas en Colombia, se hace necesario y vigente volver a ellos.

\section{Referencias bibliográficas}

Bourdieu, P. (2002). Campo de poder, campo intelectual. Itinerario de un concepto. Buenos Aires, Argentina: Editorial Montressor.

Cárdenas Rivera, M. E. (2014). Camilo Torres y Orlando Fals: antiélite, utopía y pluralismo. Colombia 19582008: lecciones para la historia. En: Fundación Colectivo Frente Unido (Coord.). Unidad en la diversidad. Camilo Torres y el Frente Unido del Pueblo (pp. 356-386). Bogotá, Colombia: Desde Abajo-Periferia.

Castillo, G. (2010). "La influencia religiosa en la ética social de Orlando Fals Borda", en Pérez Benavides, I. (2010) La influencia religiosa en la conciencia social de Orlando Fals Borda (pp. 15-23). Barranquilla, Colombia, Corporación Universitaria Reformada.

Dussel, E. (1969). El humanismo semita: estructuras intencionales radicales del pueblo de Israel y otros semitas. Buenos Aires, Argentina: Eudeba.

Dussel, E. (1973). Caminos de liberación latinoamericana II: teología de la liberación y ética. Buenos Aires, Argentina: Latinoamérica Libros.

Dussel, E. (2016a). 14 tesis de ética. Hacia la esencia del pensamiento crítico. Madrid, España: Editorial Trotta.

Fals Borda, O. (1971). La crisis, el compromiso y la ciencia. En: Herrera Farfán, N. y López Guzmán, L. (Comps.) (2012). Ciencia, compromiso y cambio social. (pp. 173-194). Buenos Aires, Argentina: Editorial El Colectivo.

Fals Borda, O. (2008/1967). La subversión en Colombia. El cambio social en la historia. Bogotá, Colombia: Fica-Cepa. (4a Edición).

Fals-Borda, O. (2007). La Investigación-Acción en convergencias disciplinares. [Discurso de Honor en la Conferencia Conmemorativa Oxfam América Martin Diskin, de la Asociación de Estudios Latinoamericanos (LASA), Montreal, 7 de septiembre de 2007]. En: O. Fals-Borda (2017). Campesinos de los Andes y otros escritos antológicos (pp. 389-400). Bogotá, Colombia: Universidad Nacional de Colombia.

Fouskas, T., Gikopoulou, P., Ioannidi, E., y Koulierakis, G. (2019). Gender, transnational female migration and domestic work in greece: an intersectional review of research on female migrants' access to labour, healthcare and community associations. Collectivus, Revista de Ciencias Sociales, 6(1), 99-134. http://dx.doi. org/10.15648/Coll.1.2019.7

Herrera Farfán, N. y López Guzmán, L. (2018). “Para mí, Camilo es el revolucionario sonriente”. Diálogos con François Houtart. En: Herrera Farfán, N. y Rojas Barragán, L. A. (Eds.). Aportes al pensamiento crítico No. 4: Camilo Torres Restrepo. Buenos Aires, Argentina: Universidad de Buenos Aires. [En prensa] 
Herrera Farfán, N. y López Guzmán, L. (Comps.) (2012). Ciencia, compromiso y cambio social (pp. 93-101). Buenos Aires, Argentina: Editorial El Colectivo-Extensión Libros-Lanzas y Letras.

Herrera Farfán, N. y López Guzmán, L. (2014). La teología de la liberación comprende la tradición religiosa popular. [Entrevista a Enrique Dussel]. Colombia: Colombia Informa. Recuperado de: http://www. colombiainforma.info/la-teologia-de-la-liberacion-comprende-la-tradicion-religiosa-popular-enriquedussel/

Hinkelammert, F. (2010). La maldición que pesa sobre la ley. Las raíces del pensamiento crítico en Pablo de Tarso. San José, Costa Rica: Editorial Arlekín.

Löwy, M. (2010). La teoría de la revolución en el joven Marx. Buenos Aires, Argentina: Ediciones HerramientaEditorial El Colectivo.

Lukács, G. (1984). Historia y consciencia de clase. México: Grijalbo.

Moreno, M. C. (2017). Orlando Fals Borda: ideas, prácticas y redes, 1950-1972. Tesis doctoral en Ciencias humanas y sociales. Bogotá, Colombia: Universidad Nacional de Colombia. [Inédita]

Pereira F., A. (2009). Orlando Fals Borda: la travesía romántica de la sociología en Colombia. En: Revista Crítica y Emancipación Año I, No. 2, pp. 211-247. Recuperado de: biblioteca.clacso.edu.ar/ar/libros/secret/ CYE/CyE2/08fals.pdf

Pérez, I. (2010). La influencia religiosa en la conciencia social de Orlando Fals Borda. Barranquilla, Colombia: Corporación Universitaria Reformada.

Rojas G., J. M. (2010). Sobre la fundación de la sociología en Colombia. En: O. Fals-Borda. Antología (pp. IXLIII). Bogotá, Colombia: Universidad Nacional de Colombia.

Sánchez, S., Pérez, V., Rebolledo., y Rodríguez, R. (2019). La cultura de paz y conflictos: implicaciones socioeducativas. Collectivus, Revista de Ciencias Sociales, 6(1), 235-250. DOI: http://dx.doi.org/10.15648/ Coll.1.2019.13

Torres R., C. (1965a). Universidad de Nariño. [Conferencia en la Universidad de Nariño, Pasto, 19 de mayo de 1965]. En: N. Herrera-Farfán y L. López-Guzmán (Comps.) (2016) Camilo Torres Restrepo. Profeta de la liberación. Antología (teológica) política (pp. 135-150). Buenos Aires, Argentina: Editorial El ColectivoEditorial Nuestra América.

Torres R., C. (1965b). Universidad Nacional. [Conferencia en la Universidad Nacional de Colombia, Bogotá, 22 de mayo y 2 de junio de 1965]. En: N. Herrera-Farfán y L. López-Guzmán (Comps.) (2016). Camilo Torres Restrepo. Profeta de la liberación. Antología (teológica) política (pp. 151-169). Buenos Aires, Argentina: Editorial El Colectivo-Editorial Nuestra América.

Torres R., C. (1970). Cristianismo y revolución. México DF, México: Ediciones Era. [Selección, notas y comentarios de Guitemie Olivieri, Óscar Maldonado y Germán Zabala] 